\section{Photo-oxygenation of Indene and 1,2-Dihydronaphthalene: Formation of 1,2-Dioxetanes and 1,2,4-Trioxanes}

Charles W. Jefford*, Toshihide Hatsui, Marcelo Ferrufino Deheza, and Gérald Bernardinelli

Abstract. The methylene blue (MB)-sensitized photo-oxygenation of indene (1) in $\mathrm{CH}_{3} \mathrm{OH}$ gave trans-2-hydroperoxy-1-methoxyindane (9), homophthalaldehyde (4), and its cyclic acetal 8 . The same reaction conducted in acetaldehyde gave only 4. Repetition of the photo-oxygenation of $\mathbf{1}$ in slightly acidic aq. acetone (1:9) gave essentially trans-2-hydroperoxy-1-hydroxyindane (14) together with some cis-5,6dihydro-3,3-dimethyl-1,2,4-trioxinol[1,2-e]indene. The MB-sensitized photo-oxygenation of 1,2-dihydronaphthalene (16) in $\mathrm{CH}_{3} \mathrm{OH}$ gave 1,4-dihydro-1-hydroperoxynaphthalene (17) and trans-1,2,3,4-tetrahydro-2-hydroperoxy-1-methoxynaphthalene (19). In acetaldehyde, 16 furnished only 17. In aq. acetone (1:9) 16 gave 17 and trans2-hydroperoxy-1-hydroxy-1,2,3,4-tetrahydronaphthalene (23). Product compositions were rationalized in terms of the 2-peroxides of the 1-cation of 1 and 16 , namely 11 and 20. Treatment of $\mathbf{2 3}$ with aldehydes and ketones on catalysis with Amberlyst-15 or trimethylsilyl trifluoromethanesulfonate afforded the trans-fused 1,2,4-trioxanes 25 . The 1,2-dioxetanes of 1 and 16 condensed with acetaldehyde on catalysis with $\mathrm{CF}_{3} \mathrm{COOH}$ to give the cis-fused 1,2,4-trioxanes $\mathbf{1 2}$ and $\mathbf{2 2}$. by Hock cleavage $(2 \rightarrow 3$; Scheme I). In other words, the initial event was assumed to be an ene-type reaction of singlet oxygen $(\mathbf{1} \rightarrow \mathbf{2})$. Later, $\mathbf{2}$ was shown not to be an intermediate as a separately prepared sample did not rearrange to 3 [3]. Subsequently, it became apparent that the product composition varies enormously with the solvent, sensitizer, and the conditions used [4]. Consequently, it is no surprise that interpretations on the mechanism of reaction have differed widely. A typical instance is provided by the photo-oxygenation of $\mathbf{1}$ in $\mathrm{CH}_{3} \mathrm{OH}$ where rose bengal (RB) in high concentration was used as sensitizer (Scheme 2) [5]. Only traces of 4 were observed, but substantial quantities of its cyclic acetal $(8,25 \%)$, cisindane-1,2-diol $(7,21 \%)$ and the transand cis-2-hydroperoxy-3-methoxyindanes $(9,34 \%$ and $10,17 \%)$ were obtained instead. All products were ascribed to a common intermediate, the 1,2-dioxetane 5. Scission accounted for $\mathbf{4}$ and 8 , while electron-transfer from RB to 5 was supposed to produce 7 . The pair of indane hydroperoxides 9 and $\mathbf{1 0}$ was thought to spring from 5 by protonation to the hydroperoxy cation 6 which was finally quenched indiscriminately by $\mathrm{CH}_{3} \mathrm{OH}$.

Recent evidence has shown that $\mathrm{RB}$ is to be shunned as a sensitizer, especially

\section{Introduction}

The dye-sensitized photo-oxygenation of olefins constitutes an important chapter in organic chemistry [1]. Depending on the olefin, reaction can occur to give hydroperoxides, 1,2-dioxetanes, and endoperoxides. These oxygenated products are of obvious synthetic value, but the manner of their formation is also important and has commanded considerable attention over the years. As a molecule for testing mechanism, indene (1) has been much studied, since its structure allows it to undergo all three of the above-mentioned reaction courses.

The first photo-oxygenation of $\mathbf{1}$ was carried out in 1968, and innocuously enough was the start of a long polemic on the nature of the primary intermediates [2]. In $\mathrm{CH}_{2} \mathrm{Cl}_{2}$, a single product, homophthalaldehyde 4 , was obtained which was thought to arise from the hydroperoxide 2

* Correspondence: Prof. C.W. Jefford Department of Organic Chemistry University of Geneva $\mathrm{CH}-1211$ Geneva 4
Scheme I

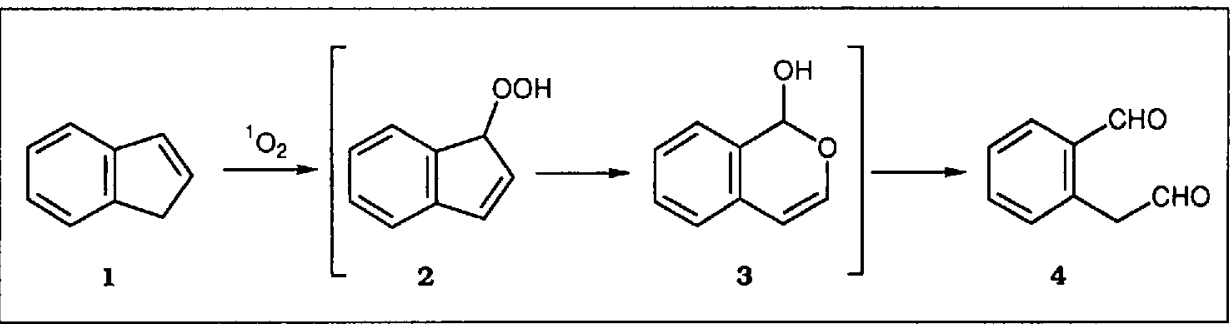

Scheme 2

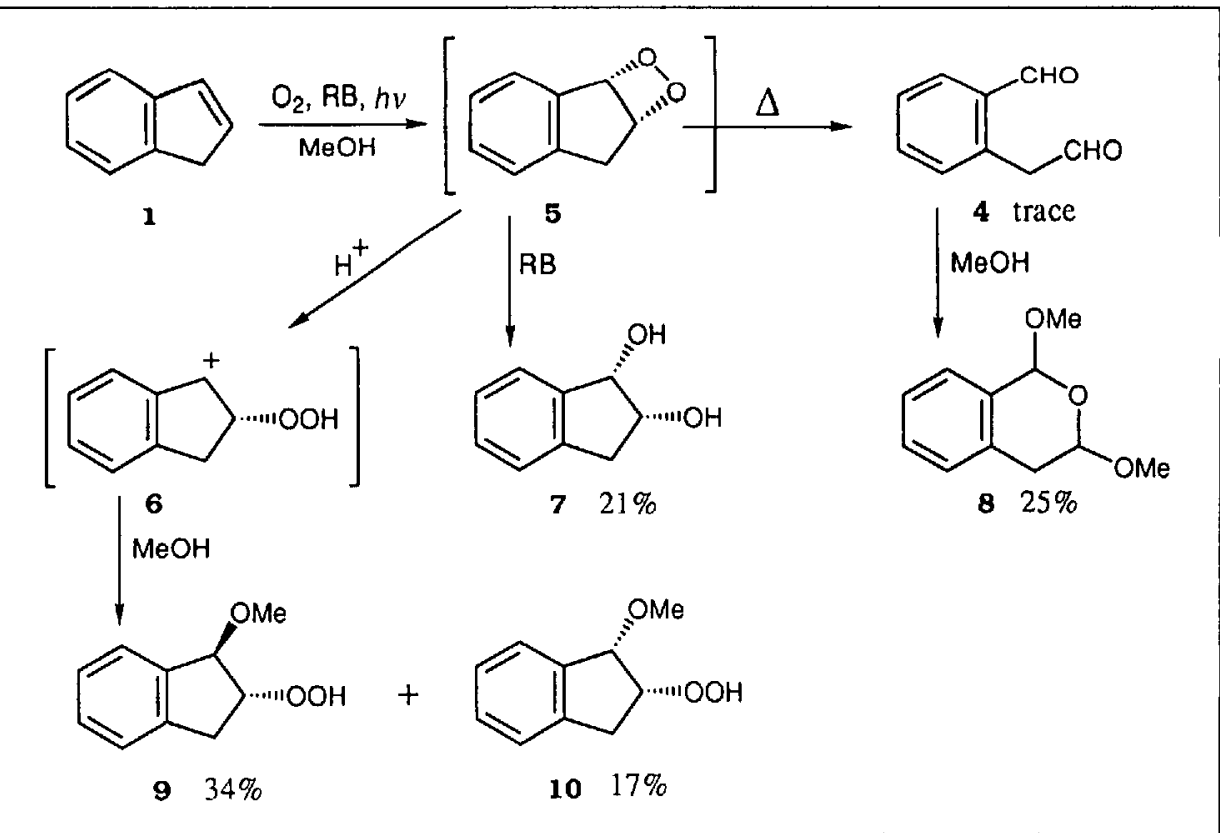




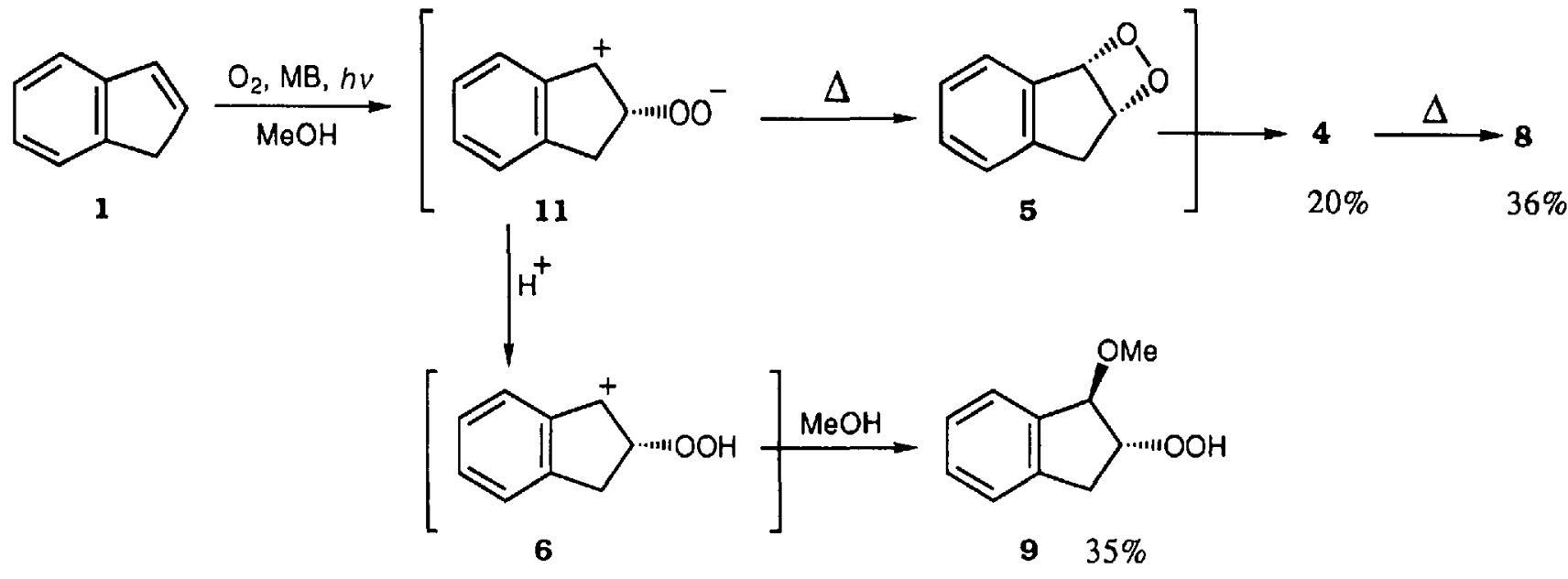

for mechanistic studies. $R B$ possesses the additional property of being able to reduce singlet oxygen to superoxide radical anion [6]. Decomposition of the latter to $\mathrm{H}_{2} \mathrm{O}_{2}$ then results in the epoxidation of susceptible olefins such as adamantylidene-adamantane. Some of the aforementioned products could have arisen from the action of superoxide radical anion or $\mathrm{H}_{2} \mathrm{O}_{2}$ on $\mathbf{1}$.

Other evidence obtained from the photo-oxygenation of 1,3-dimethylindole [7] and 2-methoxynorbornene [8] suggests that singlet oxygen reacts with electronrich double bonds to form zwitterionic peroxides as the first event. Indene (1) should behave similarly. By a suitable choice of solvent, namely $\mathrm{CH}_{3} \mathrm{OH}$ or acetaldehyde, the identity of the relevant ionic peroxides could be revealed.

\section{Results and Discussion}

We now report on such trapping experiments which have been carried out on 1 and for good measure on 1,2-dihydro-

\section{Scheme 4}

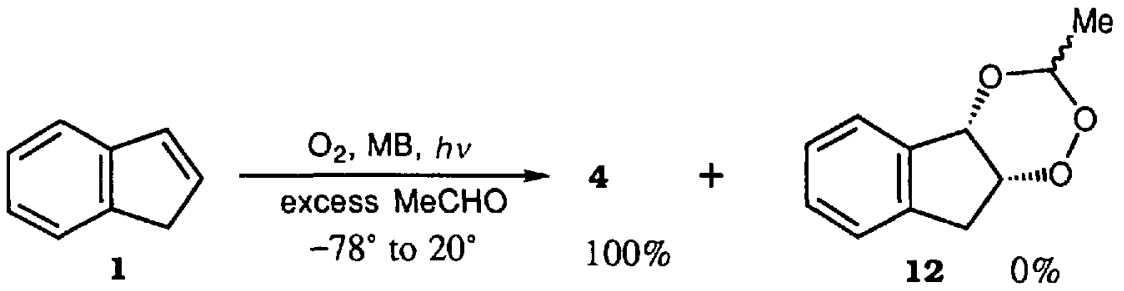

naphthalene (16) and two derivatives 26 and 27 which resemble 1 . The photooxygenation of 1 was sensitized by methylene blue (MB) in $\mathrm{CH}_{3} \mathrm{OH}$ and performed for $10 \mathrm{~h}$ at $10^{\circ}$. Three products were isolated, trans-2-hydroperoxy-1-methoxyindane $(9,35 \%)$, homophthalaldehyde $(4,20 \%)$, and the cyclic acetal $(\mathbf{8}, 36 \%)$ (Scheme 3$)$. This result indicates that a molecule of singlet oxygen has added to 1 to form the zwitterionic species 11 which enjoys stabilization as a benzylic cation. Closure to dioxetane 5 soon follows. Cleavage to- gether with methanolysis accounts for 4 and $\mathbf{8}$. Significantly, $\mathbf{1 1}$ lives long enough to undergo external capture by a molecule of $\mathrm{CH}_{3} \mathrm{OH}$. The peroxide group first acquires a proton to give the cation 6 which is then attacked on its least hindered side by $\mathrm{CH}_{3} \mathrm{OH}$ so producing 9 . The resulting trans-product does not equilibrate with the $c i s$-isomer 10 owing to the poor nucleofugacity of the $\mathrm{CH}_{3} \mathrm{O}$ group.

Repetition of the photo-oxygenation in a ten-fold excess of acetaldehyde several times at temperatures between $-78^{\circ}$ and

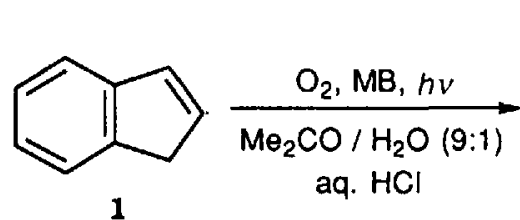
1 aq. $\mathrm{HCl}$<smiles>[CH2-][O+][C@@H]1[CH+]c2ccccc2C1</smiles><smiles>O[C@H]1[CH+]c2ccccc2C1</smiles><smiles>OO[C@H]1Cc2ccccc2[C@H]1Cl</smiles><smiles>O[C@H]1Cc2ccccc2[C@H]1O</smiles><smiles>CC(C)=O</smiles> 
Scheme 6

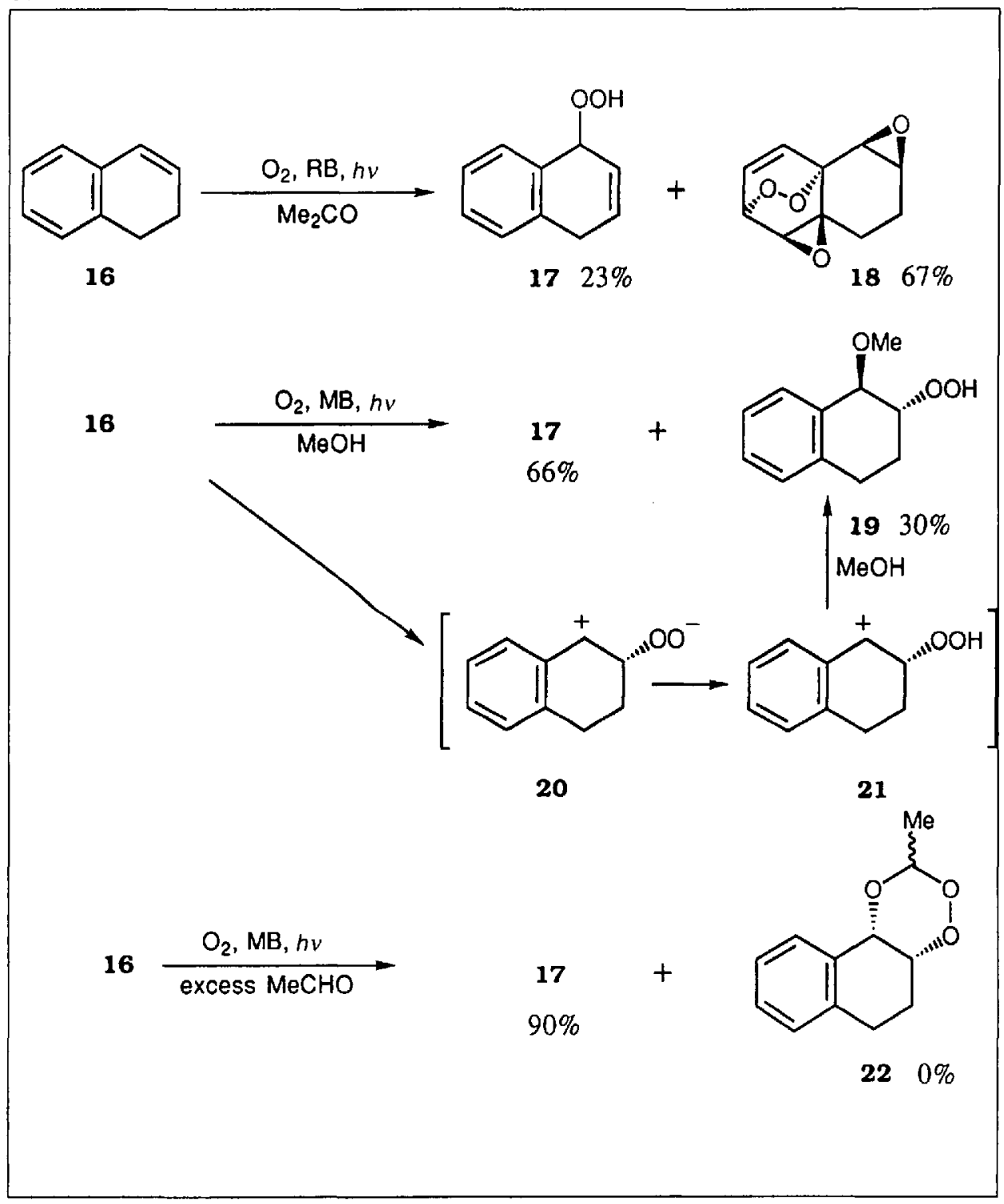

general, such hydroperoxy cations readily condense with carbonyl partners to afford cis-fused 1,2,4-trioxanes [10].

1,2-Dihydronaphthalene (16) has a structure which is similar to that of indene (1), but its photo-oxygenation has been studied less [11]. The products obtained in the RB-sensitized experiment [12] in acetone at $-78^{\circ}$ were just the 1-hydroperoxy derivative $17(23 \%)$ and the adduct of a double addition of oxygen $(\mathbf{1 8}, 67 \%)$ (Scheme 6). Re-examination of this reaction at $10^{\circ}$ in $\mathrm{CH}_{3} \mathrm{OH}$ by using $\mathrm{MB}$ as sensitizer gave a result reminiscent of that found with indene (1). The hydroperoxide $17(66 \%)$ was obtained as before, but accompanied by trans-1,2,3,4-tetrahydro2-hydroperoxy-1-methoxynaphthalene $(19,30 \%$ ) (Scheme 6). Again, the provenance of 19 can be attributed to the primary peroxidic zwitterion 20 which has successfully captured a proton and $\mathrm{CH}_{3} \mathrm{OH}$ to give successively 21 and 19 . As before, 20 could not be intercepted to give trioxane 22, even when the photo-oxygenation of 16 was conducted in an overwhelming excess of acetaldehyde (Scheme 6). Evidently, 20 and 11 are equally inert towards aldehydes. An essential difference between $\mathbf{1}$ and $\mathbf{1 6}$ is that the ene-type reaction operates for the latter as a competing mode.

In an aq. medium, acetone $/ \mathrm{H}_{2} \mathrm{O} 9: 1$ with or without a drop of $\mathrm{HCl}, 16$ reacted with singlet oxygen to give the usual ene product $17(60 \%)$ and the trans-hydroperoxy alcohol 23 (29\%) (Scheme 7). No trace of 1,2,4-trioxane 24 was detected. $20^{\circ}$ gave none of the expected 1,2,4-trioxane 12, but only 4 (Scheme 4 ). Clearly, the intermediate $\mathbf{1 1}$ is either not reactive enough or too short-lived to be intercepted by a molecule of acetaldehyde. However, when the above experiment was carried out in aq. acetone (1:9) containing traces of $\mathrm{HCl}$, trans-2-hydroperoxy-1-hydroxyindane (14) became the main product $(72 \%)$ (Scheme 5). A tiny amount of the chloro analogue $13(2 \%)$ and the $c i s$-fused 3,3-dimethyl-1,2,4-trioxane $15(7 \%)$ were also obtained. The configurations of 14 and 15 were ascertained by their reduction with $\mathrm{NaBH}_{4}$ and $\mathrm{LiAlH}_{4}$, resp., to the known trans-and cis-1,2-indane diols [9].

The origin of 15 was not the trans hydroperoxy alcohol 14 , since it did not react with acetone on catalysis with $\mathrm{Am}$ berlyst 15 or $\mathrm{CuSO}_{4}$. The trans-methoxy hydroperoxide 9 was equally inert. Obviously, the dipolar species 11 is inert towards acetone as it did not even react with the more electrophilic acetaldehyde molecule. A reasonable candidate is the hydroperoxybenzyl cation 6 which is in equilibrium with the chloro derivative 13 . In
Scheme 7

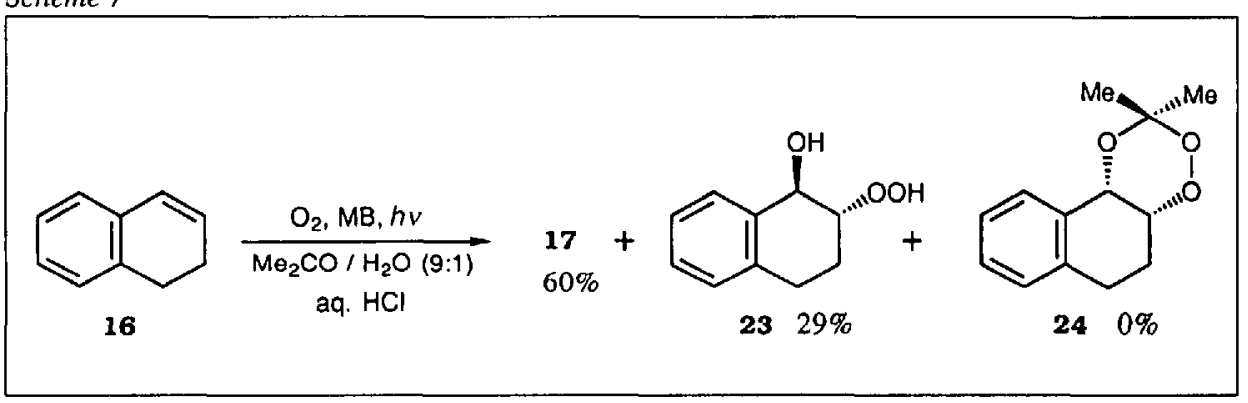

Scheme 8

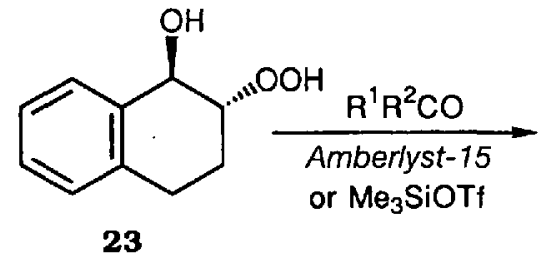

23<smiles>[R7][C@]1([2H])OO[C@@H]2CCc3ccccc3[C@H]2O1</smiles>

$2575-95 \%$ 
Varying the amount of $\mathrm{HCl}$ had no effect on the product composition.

The failure to isolate trioxane prompted further tests on 19 and 23. Like 9, 19 proved unreactive to acetaldehyde on catalysis with Amberlyst-15 or trimethylsilyl trifluoromethanesulfonate (TMSOTf) (Scheme 8). On the other hand, unlike trans-2-hydroperoxy-1-hydroxyindane (14), 23 underwent efficient condensation with both aldehydes and ketones $\left(\mathrm{R}^{1} \mathrm{R}^{2} \mathrm{CO}\right)$ on catalysis with Amberlyst-15 to give the corresponding trans-fused 1,2,4-trioxanes (25) in high yield. Several of these compounds were stable, crystalline solids which permitted their structures to be determined by $\mathrm{X}$-ray analysis [13]. The trioxane obtained from acetone $\left(\mathbf{2 5} \mathrm{a}, \mathrm{R}^{1}=\right.$ $\mathrm{R}^{2}=\mathrm{Me}$ ) revealed that the fusion of the new oxygenated ring is trans, and that the ring itself adopts a chair conformation

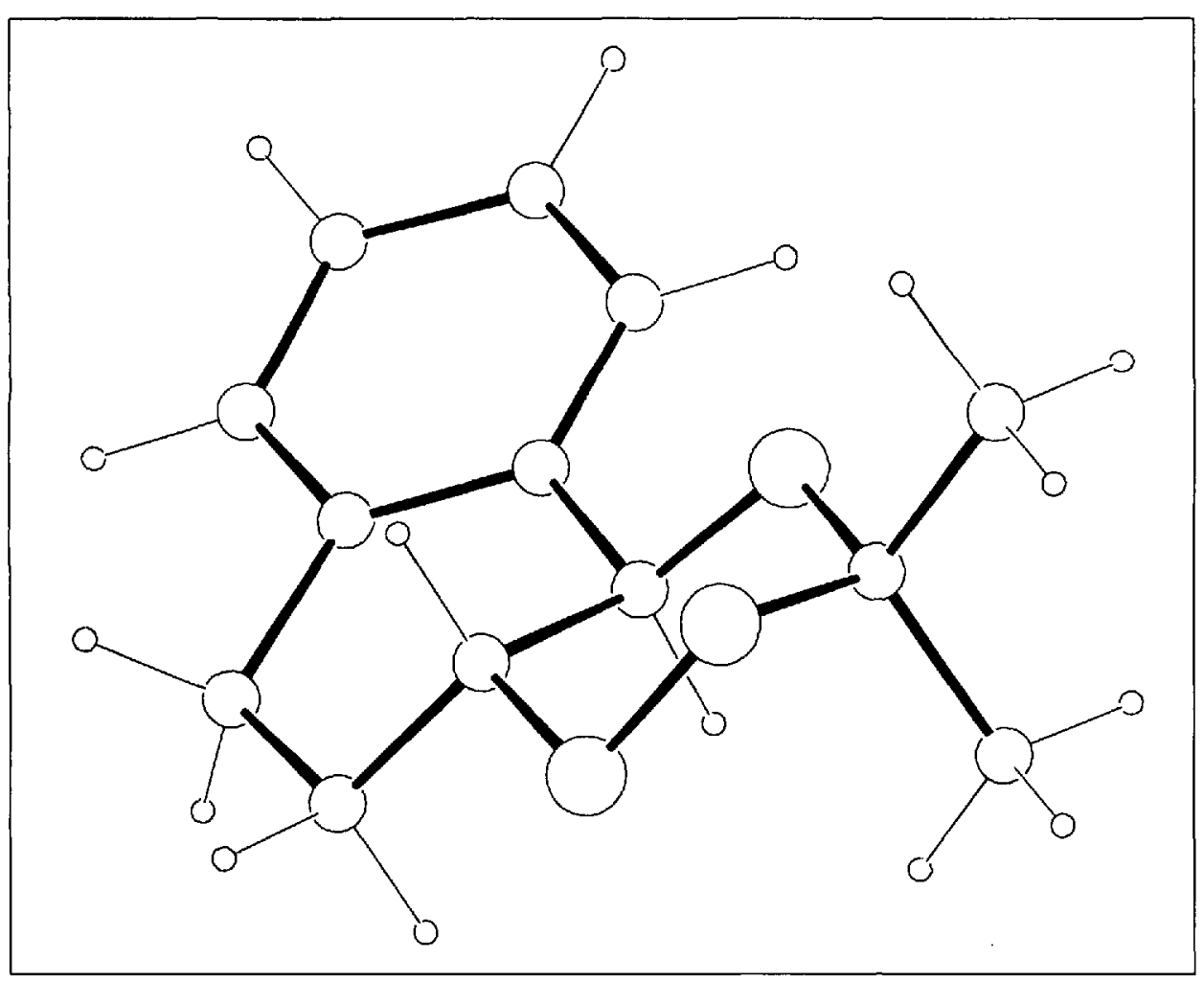

(Fig.). This result is of synthetic utility as most bicyclic 1,2,4-trioxanes prepared so far are cis-fused.

Lastly, the effect of substituents on the course of the photo-oxygenation of 16 was assayed. The 6-nitro derivative 26 proved to be totally unreactive which undoubtedly is due to the lowering of the energy of the HOMO of the styrene-like part of the molecule (Scheme 9). Conversely, the 6methoxy derivative 27 in acetone $/ \mathrm{H}_{2} \mathrm{O}$ (9:1) as solvent underwent complete reaction within $1 \mathrm{~h}$ to deliver the dialdehyde 29 $(81 \%)$ and its cyclization product $30(10 \%)$. No sign of the 2-hydroperoxy-1-hydroxy derivative analogous to 23 was seen. $\mathrm{Ob}$ viously, a capturable, discrete zwitterionmation of the dioxetane $\mathbf{2 8}$ from $\mathbf{2 7}$ is likely to be concerted.

\section{A final set of experiments was per-} ic peroxide is not formed; therefore, for-

formed with authentic samples of the 1,2dioxetanes of indene (5) [15] and 1,2dihydronaphthalene (31) [16] to rule out the possibility that they were intermediates rather than the zwitterionic species (Scheme 10). Both were inert to neutral $\mathrm{CH}_{3} \mathrm{OH}$, however, on catalysis with $\mathrm{CF}_{3} \mathrm{COOH}$ both underwent ready condensation with acetaldehyde in $\mathrm{CH}_{2} \mathrm{Cl}_{2}$ to afford the cis-fused 1,2,4-trioxanes (12 and 22) in yields of 95 and $75 \%$, resp.

\section{Conclusion}

The present results attest to the formation of zwitterionic peroxides $\mathbf{1 1}$ and $\mathbf{2 0}$, when singlet oxygen collides with indene (1) and 1,2-dihydronaphthalene (16). The positive charge in $\mathbf{1 1}$ and $\mathbf{2 0}$ is stabilized as a benzylic cation, whereas the negative charge exists simply as the free peroxide ion. The latter is easily protonated, but is unable to add to the aldehyde function. In $\mathrm{CH}_{3} \mathrm{OH}$, some of 11 escapes capture and closes to dioxetane $\mathbf{5}$. In contrast, 20 is completely captured by $\mathrm{CH}_{3} \mathrm{OH}$. Furthermore, 16 undergoes hydroperoxidation as a second course of reaction.

Both olefins 1 and $\mathbf{1 6}$ are different from 2-methoxynorbornene and 2-(methoxymethylidene)adamantane, the zwitterionic peroxides of which are readily captured by acetaldehyde [8]. However, the behavior of 1 and 16 parallels that of 2(phenoxymethylidene) adamantane which always gives 1,2-dioxetane product even in the presence of acetaldehyde [17].

A final difference between 1 and $\mathbf{1 6}$ is revealed by their ability to form $1,2,4$ trioxanes. The synthesis of both cis- and trans-fused bicyclic trioxanes (e.g. 22 and

Figure. Perspective drawing of the X-ray structure of trioxane $\mathbf{2 5 a}$

Scheme 9<smiles>COc1ccc2c(c1)CCC=C2</smiles> 


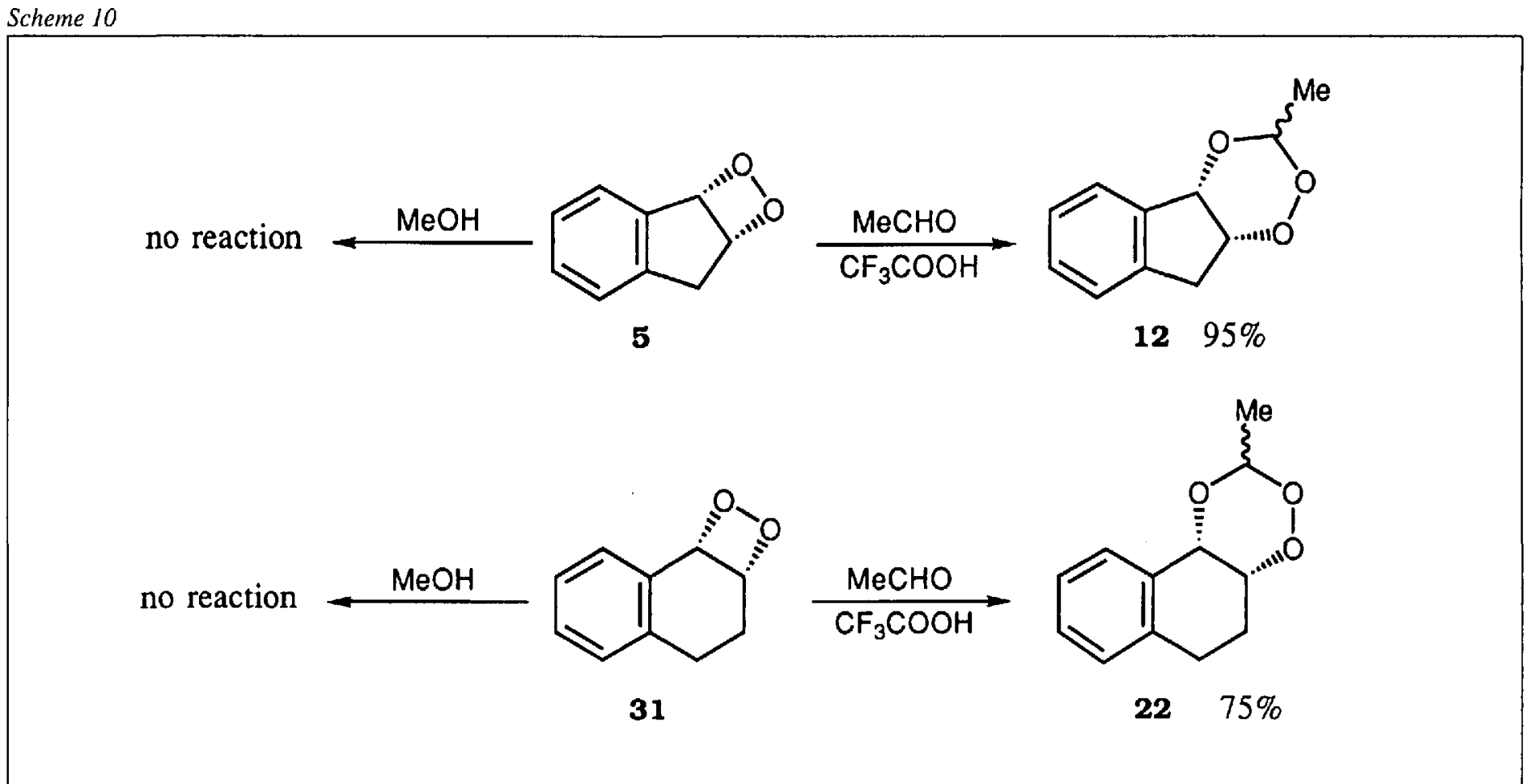

25 ) is possible for $\mathbf{1 6}$ through the intermediacy of the 2-hydroperoxy cation 21 derived from 31 and the trans-2-hydroperoxy alcohol 23, resp. Indene (1) only affords the cis-fused trioxanes (12 and 15), through the 2-hydroperoxy cation 6 . Inexplicably, trans-fused trioxanes are inaccessible.

One of us (T.H.) is grateful to Kyushu University for granting a leave of absence. We thank the UNDP/World Bank/WHO Special Programme for Research and Training in Tropical Diseases for the provision of a stipend to M.F.D.
[1] H.H. Wasserman, R.W. Murray, Eds., 'Singlet Oxygen', Academic Press, New York, 1979; RW. Denny, A. Nickon, Org. React. 1973, 133; A.A. Frimer, Ed., 'Singlet Oxygen', CRC Press, Inc., Boca Raton, FL, 1985, Vol. 2.

[2] K. Gollnick, Adv. Photochem. 1968, 6, I.

[3] W. Fenical, D.R Kearns, P. Radlick, J. Am. Chem. Soc. 1969, 91, 3396.

[4] C.S. Foote, S. Mazur, P.A. Burns, D. Lerdal, J. Am. Chem. Soc. 1973, 95, 586; P.A. Burns, C.S. Foote, S. Mazur, J. Org. Chem. 1976, 41,899 ; P.A Burns, C.S. Foote, $J$. Am. Chem. Soc. 1974, 96, 4339; J.D. Boyd, C.S. Foote, D.K. Imagawa, ibid. 1980, 102, 364 I; J.D. Boyd, C.S. Foote, ibid. 1979, $101,6758$.

[5] H. Takeshita, T. Hatsui, J. Org. Chem. 1978, 43, 3080; T. Hatsui, T. Takeshita, Bull. Chem. Soc. Jpn. 1980, 53, 2655.

[6] C.W. Jefford, M. Jiménez Estrada, G. Barchietto, Tetrahedron 1987, 43, 1737; C.W. Jefford, M. Jiménez Estrada, G. Barchietto, T. Berclaz, M. Geoffroy, Helv. Chim. Acta 1990, 73, 1653.

[7] C.W. Jefford, D. Jaggi, J. Boukouvalas, S. Kohmoto, G. Bernardinelli, Helv. Chim. Acta 1984, 67, 1104.

[8] C.W. Jefford, J. Boukouvalas, S. Kohmoto G. Bernardinelli, Tetrahedron 1985, 41, 2081.

[9] W.E. Rosen, L. Dorfman, M.P. Linfield, $J$. Org. Chem. 1964, 29, 1723.
[10] C.W. Jefford, D. Jaggi, J. Boukouvalas, S Kohmoto, J. Am. Chem. Soc. 1983, 105, 6497; C.W. Jefford, J. Boukouvalas, S Kohmoto, Helv. Chim. Acta 1983, 66, 26I5; C.W. Jefford, S. Kohmoto, J. Boukouvalas, U. Burger, J. Am. Chem. Soc. 1983, I05, 6498; C.W. Jefford, in 'Dioxygen Activation and Homogeneous Catalytic Oxidation', Ed. L.I. Simándi, Elsevier, Amsterdam, 1991, Vol. 66, p. 555.

[11] G.O. Schenck, Angew. Chem. 1952, 64, 12 .

[12] P.A. Burns, C.S. Foote, J. Org. Chem. 1973, 4l, 908 .

[13] Crystal structure determination of trioxane 25a: $\mathrm{C}_{13} \mathrm{H}_{16} \mathrm{O}_{3}, M \mathrm{r}=220.3$, monoclinic, $P 2{ }_{1} / c, a=8.926(1), b=10.040(2), c=$ 13.793(4) $\AA, \beta=106.74^{\circ}(1), V=1183.7(5)$ $\AA^{-3}, Z=4 . D_{x}=1.24 \mathrm{~g}^{-c^{-1}}, \mu=0.081$ $\mathrm{mm}^{-1}, F \mathrm{OoO}=472.1248$ measured reflections at r.t. (Philips $P W 1100$ diffractometer), 616 observed $(|F o|<4 \sigma(F \mathrm{o})), R=0.075$ by using unit weight for 145 variables. Full details of the crystal structure will be published elsewhere [14].

[14] G. Bernardinelli, M. Ferrufino Deheza, C.W. Jefford, submitted to Z. Kristallogr.

[15] L. Baumstark, C.A. Retter, K. Tehrani, C Kellogg, J. Org. Chem. 1987, 52, 3308 .

[16] R.E. Gillian, T.M. Pohl, D.L. Whalen, J. Am. Chem. Soc. 1982, 104, 4481

[17] C.W. Jefford, H.G. Grant, D. Jaggi, J. Boukouvalas, S. Kohmoto, Helv. Chim. Acta 1984, 67, 2210. 